\title{
PERCEPCIONES DEL AGUA Y MODELOS DE SU GESTIÓN EN LAS DISTINTAS FASES DE LA CONFIGURACIÓN DE DOÑANA
}

\author{
Juan Fco. Ojeda Rivera ${ }^{1}$ \\ Leandro del Moral Ituarte ${ }^{2}$ \\ Grupo de Investigación Estructuras y Sistemas territoriales (GIEST) \\ ${ }^{1}$ Departamento de Humanidades. Universidad Pablo de Olavide \\ ${ }^{2}$ Departamento de Geografía Humana. Universidad de Sevilla
}

\section{RESUMEN}

Este texto se basa en la relectura de las aproximaciones de los propios autores a la organización y ordenación territorial de Doñana desde la perspectiva de los temas del agua. Tal revisión ha conducido a la presentación de las distintas percepciones que, en los últimos siglos, se han ido teniendo sobre las aguas y, consecuentemente, de los diferentes modelos de gestión hídrica que cada paradigma o contexto perceptivo y cultural ha desarrollado. Así, de una concepción primaria que conllevaba una gestión adaptativa, en el marco de las estructuras sociales y económicas del Antiguo Régimen, se fue pasando por una percepción productivista, paralela a un modelo de gestión bonificador, colonizador y controlador. Esta trayectoria condujo al dominio del medio hídrico y a unos altos niveles de consumo, cuyas consecuencias actuales se intentan subsanar hoy —en el paradigma clorofílico— con contradictorios procesos de restauración y de trasvases.

Palabras clave: agua, Doñana, territorio, historia, percepción social, modelos de gestión.

\section{ABSTRACT}

Water perceptions and management patterns over the different stages of Doñana's conformation. This paper is based on a second reading of the approaches of the authors themselves to the spatial organisation of Doñana from water issues point of view. This review has lead to the presentation of the different water perceptions that have been arising over the last few centuries in this region. Consequently, the article refers to the different water management patterns that each paradigm or cultural and social-vision framework has developed. Thus the primary conception that encompassed an adaptive approach to water, within the social and economic context of the Antiguo Regimen, 
gradually changed into a productivist perception, parallel to a kind of reclamation and controlling management model. This evolution gave rise to nature control and to high levels of water consumption, whose current consequences we are trying to alleviate nowadays — within the 'clorophilic' paradigm — with contradictory processes of water restoration and interbasin transfers.

Key words: water, Doñana, territory, history, social perception, management patterns.

\section{Introducción}

Cuando se habla del mundo de Doñana, debe pensarse siempre en un espacio caracterizado por la complejidad, el dinamismo y la conflictividad. Tales caracteres se sostienen en su propia condición de territorio híbrido - en el que se mezclan elementos físicos, económicos, sociales y culturales muy variopintos, engendrando un espacio de fronteras y de encuentros entre ecosistemas, economías, sociedades y culturas- y como territorio colonial y no acabado - ni en su configuración física (dunas que avanzan, marisma senescente...) ni en su percepción económico-social (importante cambio de valor en las últimas décadas, en las que muchas limitaciones pasaron a convertirse en recursos) ni en su propia organización administrativa (multiplicación de entes administrativos y gestores)—.

En este mundo que se está haciendo — «terra in fieri», que dirían los latinos o la «Argólida», según Caballero Bonald - las aguas superficiales y subterráneas, como las arenas, los lodos más o menos tóxicos y todos los fluidos fluyen hacia el Parque Nacional, cuyo propio emplazamiento al final de una desembocadura le otorga un papel de embudo difícilmente soportable por un sistema de valores que confunde sistemáticamente crecimiento económico con desarrollo y opone tales categorías a la de conservación de la naturaleza, aunque teóricamente utilice argumentos y paráfrasis armonizadoras, como el socorrido «desarrollo sostenible». El Parque Nacional de Doñana se convierte así en un desafío, en un reto y en un crisol del propio sistema económico que se permitió el «lujo útil» de declararlo como tal en unos momentos predemocráticos.

Mientras que el régimen franquista mostraba al mundo su apertura con la declaración de Doñana como Parque Nacional (1969), en Francia se debatía democráticamente la oportunidad de hacer lo mismo con Camarga — espacio deltáico mediterráneo, de diferentes características que el estuarino atlántico de Doñana-, llegándose a la conclusión de que era preferible no adoptar sobre un territorio de desembocadura un tan alto nivel de protección y dejándolo en Parque Natural Regional, a pesar de su potente percepción simbólica y representativa. Será difícil, por no decir imposible, encontrar otro Parque Nacional europeo al final de un embudo de aguas, de arenas, de efluentes y vertidos. El máximo grado de protección, en territorios de vieja civilización en los que el hombre está secular y permanentemente presente, suele aplicarse a espacios isleños o situados en áreas cimeras.

De tales contradicciones inherentes a este complejo mundo quiere dar explícita fe el análisis que aquí se pretende abordar sobre las distintas percepciones del agua en Doñana a lo largo de la historia reciente.

\section{Hipótesis de trabajo}

La relectura de nuestras propias aproximaciones al análisis de la organización y ordenación territorial de Doñana y su entorno (OJEDA, J.F. 1985, 87, 90, 92, 93, 94, 99a, 99b, 
2000) y de su enfoque desde el tema del agua (MORAL 1989, 90, 91, 93a, 93b, 2002), nos ha conducido a presentar las siguientes hipótesis de trabajo sobre las distintas percepciones que, en los últimos siglos, se han ido teniendo sobre las aguas y, consecuentemente, sobre el modelo de gestión que cada paradigma o contexto perceptivo y cultural ha desarrollado en torno a las mismas:

A.- Durante el Antiguo Régimen, época de marginalidad productiva y de marginalización voluntaria de las tierras de Doñana — débiles para producir agrícolamente, pero ricas en recursos recolectables_- época de orden señorial y concejil —ordenanzas ducales y concejiles, pactos y pleitos por la jurisdicción y el uso de los recursos territoriales-, época de escaso desarrollo de las fuerzas y los medios productivos — poca población, insalubridad e incapacidad de dominio técnico de arenas y arcillas-, en este mundo de Doñana dominaba la naturaleza, uno de cuyos elementos más conspicuos era precisamente el agua, a la que, a veces, se esperaba ansiosamente y, otras veces, se temía. La ordenación territorial y productiva procuraba adaptarse a las circunstancias cambiantes, en ocasiones imprevisibles, de año seco, año húmedo, sequía, inundación, agua salada, agua dulce...buscando estrategias micro y macro escalares. En definitiva las palabras clave que podrían categorizar esta primera fase tradicional en la configuración de Doñana, serían las siguientes: Marginalidad y orden señorial. Predominio de la naturaleza. Gestión adaptativa del agua.

B.- Los planteamientos ilustrados se dejan notar en Doñana desde fines del siglo XVIII e inicios del XIX, proponiendo la necesidad de convertir estas tierras predatorias en tierras productivas, a través de unos proyectos y programas de fomento - provincia de Sanlúcar de Barrameda, colonizaciones agrarias y forestales, desecación de marismasque siempre contemplan el control del agua. El paradigma romántico — extendido desde mediados del siglo XIX hasta la mitad del XX - descubre los valores naturalisticos, paisajísticos y científicos de Doñana, planteando la necesidad de la protección pionera de su naturaleza. Paralelamente, durante la primera mitad del siglo XX, se desarrollan unas intervenciones sobre dunas, marismas y arenales que encuentran justificación en argumentos «cosmológicos» (ecológicos) y, posteriormente a la guerra civil, en razones económicas nacionales (autárquicas). Los conceptos clave de esta segunda fase serán, pues: Fomento ilustrado de la producción, frente a protección pionera y romántica de la naturaleza. Bonificación de marismas, desecación de lagunas, primeros intentos de puesta en riego, detención de dunas. Gestión controladora del agua.

C.- El marco desarrollista de los años 60 y 70 del siglo XX se caracteriza en este mundo de Doñana por su descubrimiento masivo como espacio de nuevas producciones: agricultura intensiva en arenas, turismo playero, naturaleza visitable. Las prospecciones de agua subterránea, efectuadas por la FAO desde finales de los años 50, se saldan con el éxito del encuentro de una gran «bolsa de agua» (acuífero 27) que, según las previsiones efectuadas entonces podía cambiar el rostro de esta comarca marginal y constituir su gran riqueza futura: miles de hectáreas de regadío sobre arenas tradicionalmente improductivas. Las playas atlánticas del Coto de Doñana, de blancas arenas, constituirán, por su parte, uno de los escenarios del Plan de Desarrollo Turístico de la costa de Huelva. El Rocío y el propio Parque Nacional de Doñana funcionarán como otros tantos focos de atracción turística. Las aguas, tanto superficiales como subterráneas, se convierten en esta época -como elementos relacionantes de los espacios agrícolas, recreativos, turísticos y naturales- en factor de conflicto. Descubrimiento del agua subterránea y de la playa. Masificaciones de los usos: Regadíos/Naturaleza/Turismo. Gestión dominadora, despilfarradora y conflictiva de las aguas. 
D.- En la actual etapa democrática, iniciada con la Ley de Doñana (Diciembre 1978), se ha ido pasando de una primera fase caracterizada por las compensaciones al entorno por haber cedido al mundo el patrimonio de Doñana, a un segundo momento en el que se busca la integración de Doñana en una comarca europea periférica y subvencionada para que logre un paradigmático «desarrollo sostenible». Las contradicciones de esta situación se manifiestan de muchas formas, pero aquí debe destacarse la manifestación de tales contradicciones en la actual y proyectada gestión importadora del agua, en función de la emergencia económica (agricultura, turismo) y ecológica (parques) de este espacio. La conciencia del despilfarro de la etapa anterior no ha conducido a una gestión educadora, sino a planes de importación de agua desde comarcas vecinas para compatibilizar regadíos, turismo masivo y naturaleza conservada. Compensaciones, integración, «sostenibilidad», restauración del sistema hídrico, trasvase y gestión importadora del agua son, pues, las palabras clave de la actualidad.

\section{El agua en el Antiguo Régimen: gestion adaptativa}

El mantenimiento de estos parajes al margen de los mecanismos productivos de los modelos económicos dominantes, hasta principios del siglo $\mathrm{XX}$, es condición primera e indispensable de sus designaciones posteriores como espacios protegidos.

En Doñana, las arenas estériles - fijas o volanderas-, las marismas saladas o salobres y los matorrales halófitos y xerófitos constituyen, durante todo el Antiguo Régimen, el soporte de actividades predatorias, marginales al modelo agrícola tradicional dominante. El campo de batalla entre un gran río - Guadalquivir - y un gran mar - Atlántico- que es Doñana está tan marcado por los dinamismos de aguas saladas y salobres, de arenas móviles marinas y arcillas impermeables fluviales, de «maresías» selectivas y dominantes, que marca el ritmo de su posible y respetuosa explotación predatoria humana.

Su propia posición en el señorío de Medinasidonia - entre las tierras gaditanas de Sanlúcar de Barrameda y las tierras condales de Huelva-Niebla- otorgan a Doñana durante esta época señorial el papel de lugar de paso. El camino fundamental del señorío (Sanlúcar-Niebla) y algunos de los caminos importantes del reino de Sevilla (MoguerSevilla y Sevilla-Aljarafe-el mar) atraviesan y se cruzan en Doñana, que aparece para el caminante como un desierto estival o como un pantanal insano y rico a la vez, en invierno. La Vera —ecotono diversificado y rico de surgencias freáticas, de «ojos» y pozos, de chozas y hatos- es el bebedero y descansadero de la fauna y del hombre y es también sostén de aquella red caminera, con sus arenosas «rayas reales» de uso invernal — cuando la marisma está inundada - y sus arcillosos y marismeños caminos veraniegos. El agua, con su presencia o ausencia, con su inundación y su sequía, marca pues también el paso por estos caminos tradicionales de Doñana. Por ello, resultan machaconamente repetitivas las preocupaciones de los duques (ordenanzas) y de los concejos municipales (actas capitulares) por el cuidado de los puentes y por las limpiezas de los serpenteantes arroyos, procurando su buen fluir.

Los Taranjales, La Palmosa, el Partido y, sobre todo, la Rocina — con su bosque galería de sauces, sanguinos y mimbres peculiarmente aprovechables para arcos de toneles, pipas y botas - constituyen otros tantos arroyos de Doñana, en los que se mezclan aguas superficiales con veneros y se extienden formando trenzas, canales, algaidas y charcos, generando unos cursos anchos, híbridos y cambiantes.

La agricultura tradicional permanente practicada en los pueblos de Doñana se suele circunscribir a los terrenos terciarios en los que se emplazan los núcleos poblacionales (ruedos) y es de secano, aunque se constatan presencias testimoniales de huertas y huertos 
FiguRa 1. Sistema hidrológico natural de Doñana

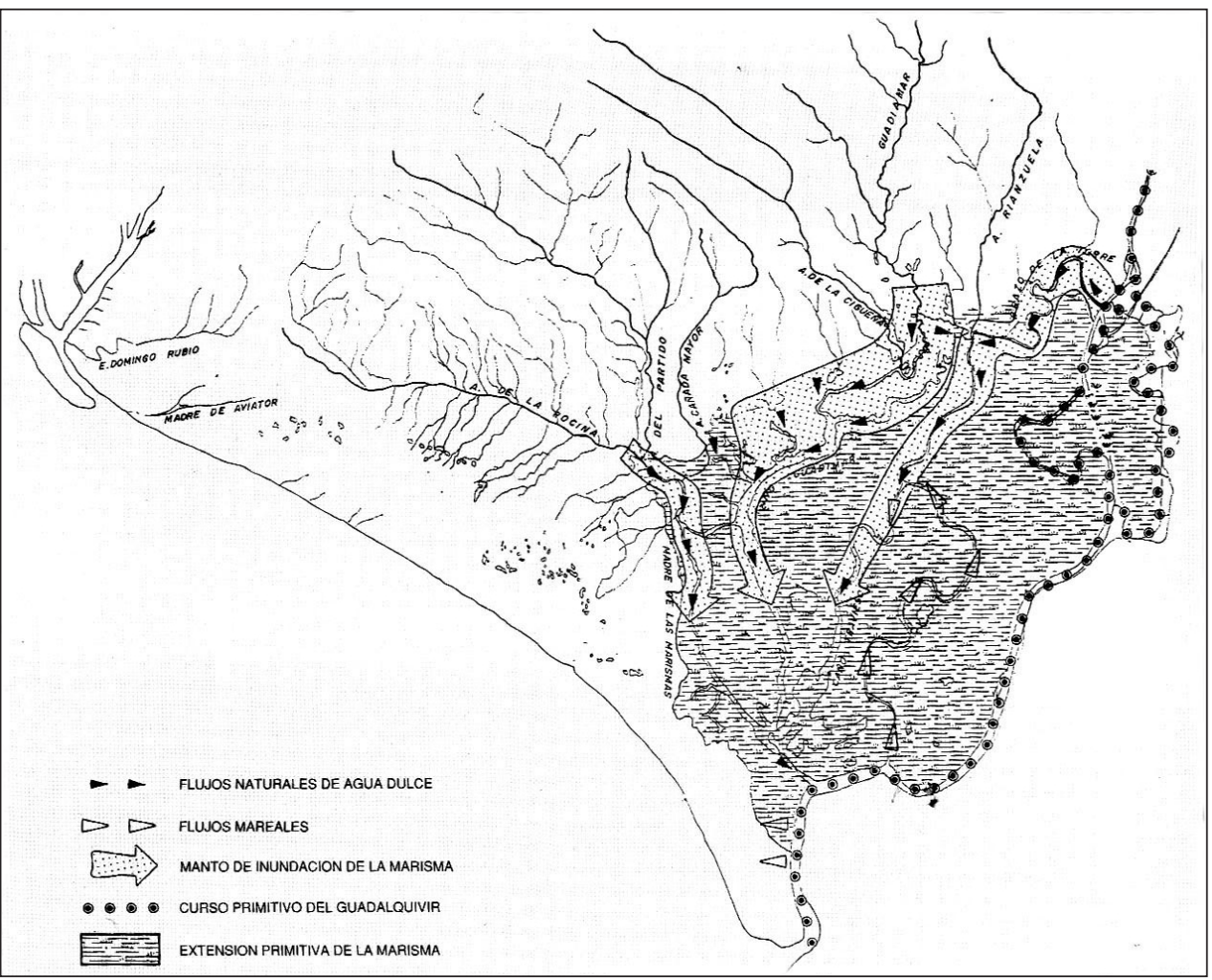

Fuente: Plan Director Territorial de Coordinación de Doñana y su Entorno, 1989.

de regadío, que ocupaban los bajos arenosos de los arroyos y cumplían una función autoabastecedora. Pero también se practica —en suertes repartidas en los baldíos comunales o en las tierras concejiles - la agricultura de roza, que tiene la virtualidad de hacer descubrir a los campesinos del entorno de Doñana las antiguas vegas relictas y colmatadas por los mantos eólicos cuaternarios, que se constituyen en los parajes apetecidos para la siembra y para unos posibles y reivindicados repartos de tierra. El agua - no visiblemente fluyente, pero percibida en las ricas producciones cerealísticas obtenidas en arenales- se convierte así, también, en marcadora selectiva de unos parajes aprovechados mediante una agricultura muy extensiva y de secano.

La inundabilidad invernal de la marisma es, asimismo, causa de la trasterminancia ganadera, perfectamente normalizada por las ordenanzas señoriales y por las hermandades de pasto entre poblaciones del Condado y la Marisma: Dehesas —arenales perimarismeños - marismas constituyen los eslabones espaciales de la cadena trasterminante anual del ganado en el mundo de Doñana.

Las condiciones para la caza en Doñana son absolutamente favorables: monte plagado de acebuches, madroñeras, brezales, tojos y cantuesos, abundancia de lagunas y charcos y presencia de una marisma cíclicamente inundada, ausencia de grandes asentamientos hu- 
manos e incluso pagos de roza, que dejan muchos granos sueltos tras las cosechas, constituyen factores determinantes de una gran riqueza cinegética. Pero dicha caza también está marcada por el agua como factor determinante. Así, mientras que en los matorrales tanto la vegetación como el recurso y la propia actividad cinegética se caracterizan por la permanencia y madurez, en las cíclicas marismas todo es dinamismo y fluctuación. Las variaciones del régimen hídrico van acompañadas de una marcadisima estacionalidad, que hace cambiar el paisaje desde un auténtico mar interior en invierno hasta una estepa desértica en verano. Tal sistema inmaduro, con gran protagonismo del medio físico y del agua, provoca acumulaciones temporales de biomasa, que exigen a la rica ornitofauna marismeña unos patrones de distribución espacio-temporal muy marcados. El aprovechamiento de estos recursos por el hombre se convierte, como toda actividad marismeña, en una tarea estacional y cíclica en la que se suceden:

- Caza invernal de los migradores gansos y patos, que van llegando desde finales de octubre.

- Recolección de huevos y crías de gallaretas (fochas), que empiezan a anidar con la primavera temprana y pueden efectuar hasta cuatro puestas.

- Caza «a la bulla» de patos y fochas jóvenes o de patos mancones, que ya a comienzos de verano se acumulan en los pocos puntos de agua que quedan. Y a esperar la invernada para cerrar el ciclo.

Las pesquerías fluviales, marismeñas y lagunares, así como la pesca marítima o las salinas son otras tantas actividades predatorias vinculadas a las aguas saladas, salobres y dulces y, en muchos casos, relacionadas - como la caza o los pastos - con pactos entre la casa señorial y las poblaciones de Doñana. El señor aprovechaba los recursos más valiosos - atunes, caza mayor, sal, alquiler de pastos de sus dehesas privilegiadas- y permitía a sus súbditos explotar los recursos menores — sardinas, peces fluviales y de caños, caza menor, pastos abiertos-.

En este mundo tradicional de Doñana - como en Macondo- las cosas eran tan primitivas que no tenían nombres, sino que se les señalaba con el dedo. Una aproximación etimológica a este espacio anfibio de Doñana nos muestra muchos nombres comunes vinculados al agua - lucio, veta, pacil, algaida, arroyo, laguna, charco, caño, ojo, fuente, frial...- y también algunos nombres propios especialmente significativos de sus respectivos contextos: Taranjales y Palmosas — vegas relictas de especial productividad agrícola-, Laguna Dulce — distinguida en el rosario de lagunas postdunares-, El Perchel y la Canaliega — artes de pesca practicadas en las bocas de la Rocina-. Pero entre todos ellos destaca uno por su clara alusión microclimática — condensación nocturna diaria por inversión térmica-y por su potencia simbólica — pequeña irrigación natural que permite mantener cierto oasis veraniego y que le da nombre al signo sagrado de aquel espacio-: El Rocío.

Puede decirse, pues, que durante la fase tradicional de configuración de este territorio existe una percepción muy clara de su carácter anfibio y de cómo los ciclos de presencia/ausencia de agua o de salinidad/no salinidad de la misma exigen al hombre adaptaciones complementarias, estacionales y dinámicas de sus estrategias predatorias o productivas.

\section{El agua en la Ilustración, el Romanticismo y la Autarquía: gestión controladora}

La progresiva consolidación de dos concepciones del orden territorial difícilmente conciliables (productivismo agricolista, tecnocrático y populista, frente a conservacionis- 
mo ambientalista, estético y elitista) irá conduciendo a la vinculación de cada recurso a unos parajes especializados en su explotación o conservación y a un control del agua.

Tal proceso será inseparable de la presencia del Estado como instancia máxima de gestión pública en el ámbito territorial de Doñana en el que más que diferenciarse se acentúan los rasgos generales característicos de los grandes humedales litorales mediterráneos. Los caracteres hidrológicos y edafológicos de las marismas del Guadalquivir se extreman en función de un régimen pluviométrico muy torrencial, un marcado estiaje y una profunda penetración de las aguas marinas — propia de su carácter atlántico — en el interior de la formación estuarina (la onda de marea se deja sentir a 110 kilómetros de la desembocadura del Guadalquivir, aguas arriba de Sevilla, donde la carrera de marea alcanza los 2,5 metros) (VANNEY, 1970; FERNÁNDEZ PALACIOS, MARTOS y RUBIO, 1990). Todo ello ocasiona que a las dificultades habituales de gestión de los humedales litorales por su inestabilidad, la sucesión en el tiempo de terrenos inundados y terrenos calcinados y la salinidad de suelos y aguas, se añada aquí una especial carestía de los recursos hídricos en los momentos en los que la estrategia de explotación agraria los hace necesarios. En definitiva, una problemática que no es original, pero sí más extremada que las que aparecen en espacios comparables (marjales levantinos, deltas del Ebro y Po o Camarga). Un medio natural más resistente a la penetración humana en un contexto territorial, la Baja Andalucía, en la que por motivos geo-históricos en los que no podemos entrar (ver MORAL, 1991 y 1994), se produce una menor intensificación de la explotación del medio y un retraso en la colmatación del espacio productivo respecto de otras regiones de la cuenca mediterránea europea. De esta manera, la colonización de Doñana ha exigido profundas transformaciones ecológicas, especialmente el cambio del sistema hidrológico natural, que sólo se ha podido realizar plenamente por medio de un desarrollo tecnológico y una concentración de recursos económicos alcanzada en momentos relativamente recientes y bajo los auspicios del Estado.

Así, por ejemplo, la margen izquierda del sistema marismeño del Guadalquivir, la gran zona regable denominada Bajo Guadalquivir, depende para su abastecimiento de una derivación de 60 metros cúbicos por segundo realizada muy aguas arriba, en Peñaflor en el límite de la provincia de Córdoba, desde donde es conducida por un canal de $150 \mathrm{kms}$. de longitud, cuya ejecución, condicionada a la regulación previa de la cuenca, es expresión de las condiciones geográficas de la colonización de la Marisma. Nada parecido a los bombeos directos a pie de dique de las abundantes aguas del Ródano para el riego de los perímetros cultivados en la Alta Camarga o las cortas derivaciones necesarias para el riego del delta del Ebro o, incluso, la derivación de las abundantes aguas de estiaje del Júcar para el riego de sus vegas y de los terrenos conquistados a la Albufera de Valencia.

Para que algo parecido a esto haya sido posible en las marismas de Doñana — caso de los actuales bombeos directos que alimentan el arrozal de las islas centrales (Isla Mayor, Menor y Mínima) — se ha tenido que completar la rectificación del cauce del estuario, con alteración de las funciones hidráulicas de los antiguos brazos divagantes, intervención que se produjo buscando la mejora de las condiciones de navegación. A esto se añade un manejo, ya con intención agraria, de la dinámica salina del mismo estuario —en el que la concentración del flujo en un solo brazo establece una zona de transición entre agua dulce y salada denominada tapón salino- que ha de contar como condición imprescindible con una importante capacidad de gestión hidrológica del conjunto de la cuenca, que todavía hoy dista de ser completa.

En tal marco de referencia, las primeras intervenciones puntuales ilustradas, conducentes a ir convirtiendo estos «espacios predatorios» en «territorios productivos», son la repoblación con pinares de la Algaida de Sanlúcar y el sur de Doñana (1737-39) y las 
implantaciones ducales de colonias agrícolas en Marismillas (navazos) y El Rocío (huertas). Pero los primeros planteamientos planificadores y técnicos modernos de este territorio y de sus aguas aparecen explícitamente en el Plan Ilustrado de Fomento de la provincia de Sanlúcar de Barameda, firmado en 1805 por Francisco de Terán — de la Sociedad Económica de Amigos del País, de Sanlúcar-, en el que se diagnostica el territorio que se extiende entre las desembocaduras del Guadalquivir y el Guadiana, destacando por «sus inmensos terrenos sumergidos en marismas y pantanos» y por «los desiertos abandonados a las producciones espontáneas y cubiertos de malezas, comúnmente conocidos como baldíos», pero también por «las potencialidades que le confieren su topografía plana, la influencia marina y la presencia en él de tres desembocaduras (Guadalquivir, Odiel-Tinto y Guadiana) fluviales». El desagüe, la bonificación colonizadora y su conversión en propiedad privada mediante reparto entre braceros son los mecanismos para transformar estas grandes áreas incultas en tierras de pasto y labor. El fomento de las pesquerías y de sus manufacturas, la adopción de los últimos adelantos en máquinas industriales y el fomento del comercio interior y exterior, a través de la colaboración de cada municipio en la construcción de caminos, puentes, muelles y caños de navegación serán los complementos necesarios de la colonización agrícola y constituirán unos puntos que «abrazan en globo el plan de fomento que S.M. se propone en la nueva provincia marítima de Sanlúcar de Barrameda».

La idea de una bonificación de los terrenos marismeños del Guadalquivir y de su conquista para la agricultura seguirá prevaleciendo durante todo el siglo XIX y sucediéndose los proyectos grandilocuentes vinculados a la navegación por el río y a la desecación y colonización de las marismas. Ingenieros, agraristas y otros técnicos del progreso, pertenecientes a empresas extranjeras o nacionales, consideran estos espacios como «desiertos» o «charcas pestilentes» que deben ser valorizados y explotados según criterios de higiene (bonificación de marismas y desecación de lagunas), cosmología (detención de dunas móviles) y/o productividad (arenales). Estos proyectos, que irán resultando viables o no, en función de los avances técnicos -incorporación de los sistemas de polderización holandesa y de técnicas de desalinización de suelos - tienen por objetivos la obtención de máximos beneficios de la explotación de un recurso concreto y la progresiva apropiación privada de los baldíos comunales, pero son presentados como los únicos caminos hacia el progreso y desarrollo de una zona que debe ser domesticada por la agricultura o el sector forestal, que controlarán y regularán sus aguas convirtiéndolas de limitantes y peligrosas en recurso estratégico.

En esto las marismas del Guadalquivir no se diferencian de la percepción que se venía teniendo de los humedales litorales del sur de Europa. Espacios en los que la intervención humana habría de tornar el caos, el abandono, el retraso y la insalubridad por el orden, la prosperidad, el progreso y la higiene (BETHEMONT y VILLAIN-GANDOSSI, 1987). Espacios en los que los colectivos o instituciones que asumen el protagonismo de la transformación se encuentran con la posibilidad de intervenir sin trabas, sin estructuras preexistentes que condicionen su gestión. Con la posibilidad de crear — en la medida en que la empresa consiga dominar las constricciones del medio físico marismeño y su balance financiero sea positivo - una nueva organización del espacio y unas relaciones sociales inéditas (PICON, 1978 y 1985).

Sin embargo, la perspectiva bonificadora chocó con la oposición de otras interpretaciones que expresaban formas distintas de intervención económica en el espacio marismeño y que defendían relaciones sociales diferentes de las que los planes de puesta en valor trataban de introducir. Destacan en este sentido las actividades y el discurso de los beneficiarios de los aprovechamientos tradicionales que, impulsados por la defensa de unos 
intereses amenazaos por cambios jurídicos que pudieran acompañar a las transformaciones, expresan una lectura diferente de los recursos del territorio y del paisaje. Es ilustrativa de esta posición la respuesta entre irónica e indignada que daba en 1858 Nicolás Sancho, portavoz de los criadores de ganado de Sevilla, a los promotores de proyectos coetáneos de saneamiento de marismas. Frente a la perspectiva de estos últimos que sólo veían terrenos «incultos y abandonados, anegados, despreciable y de escasísimo valor», Nicolás Sancho defiende su productividad natural y sus imprescindible funcionalidad en el sistema económico agroganadero tradicional (SANCHO, 1858).

Coetáneamente a los proyectos e intervenciones de fomento y a los consiguientes conflictos con los protagonistas de los anteriores sistemas de aprovechamiento, comienza la historia de la percepción o descubrimiento de estos territorios y estas aguas como territorios y aguas a conservar en su estado original. Tal percepción queda enmarcada en el paradigma romántico y vinculada a los viajeros burgueses que los consideran como paisajes excepcionales, elevándolos a la categoría de «mitos» de la naturaleza salvaje. A esta consideración se sumarán las nuevas ciencias, que van poniendo en evidencia la excepcional productividad biológica de los humedales. Es conocida la trayectoria de progresivo aumento de la conciencia sobre la riqueza biológica de las marismas del Guadalquivir, que arranca del Catálogo de las aves observadas en algunas provincias de Andalucía» de Antonio Machado y Núñez (1854) y se prolonga en la larga serie de personalidades e intervenciones institucionales que han dejado su huella en el proceso de valoración científica y cultural de estos espacios. Desde los ornitólogos Howard Saunders y Lord Lilford (1864) hasta los decisivos trabajos de José Antonio Valverde en las décadas de 1950 y 1960 (VALVERDE, 1990).

Doñana se convierte en una inversión cultural de la burguesía comerciante gaditana, propietaria del coto desde 1897 y arrendataria de su cacería: Expediciones deportivovenatorias (Ford, Murray), recuperación de la tradicional trayectoria de cazadero real (lanceos de Alfonso XII y XIII), ejecución de una labor publicitaria y científica (Chapman y Buck), patrocinio de excavaciones que buscan raíces nobles (Schulten y Bonsor) y establecimiento de una zonificacion del cazadero (Pabellones de caza o «palacios» en matorrales, marismas y pinares-dunas).

El enfrentamiento entre dos concepciones del territorio difícilmente conciliables (productivismo tecnocrático, colonial y populista frente a conservacionismo estético, colonial y elitista) está servido en Doñana desde los inicios del siglo XX y tendrá sus expresiones más radicales en momentos álgidos de confrontaciones sociales como son la II República frente populista (intentos de expropiación y reparto de Doñana por el I.R.A. enfrentados a la intención de convertirlo en parque nacional de Turismo) y la época autárquica franquista (fuertes intervenciones colonizadoras —arroz, eucalipto, guayul... y atomización del territorio en islas productivas y desarticuladas, pero también con grandes logros: marisma arrocera, pinares litorales y arenales baldíos madereros).

En relación con el agua, ha ido dominando en esta larga etapa la necesidad de controlarla y regularla, para evitar sus peligros (inundaciones o enfermedades) y para ordenar sus aprovechamientos tanto agrícolas como forestales y turísticos. En el sector oriental (Marismas de Trebujena, Lebrija y Los Palacios) y las islas centrales (Puebla del Río) el proceso de transformación se remonta a principios del siglo XIX y es bien conocido. Desde los proyectos de acondicionamiento agrícola, industrial y naviero de la Compañía de Navegación del Guadalquivir en 1818 hasta las actuaciones de la Compañía Islas del Guadalquivir y su sucesora Compañía Hispalense de Valoración de Marismas — con uno de sus hitos más destacados en 1928, año en el que Alfonso XII pone la primera piedra del poblado que llevará su nombre-, se sucede una larga sucesión de intervenciones que han sido reitera- 
damente analizadas desde diferentes puntos de vista (GRANDE COVIÁN, 1978, REGUERA RODRÍGUEZ, 1985, OJEDA RIVERA, 1987, MORAL ITUARTE, 1991, GONZÁLEZ ARTEAGA, 1993).

En el sector occidental de las marismas que forman y rodean el actual Parque de Doñana (Marismas de Aznalcázar, Hinojos y Almonte), aunque también existen antecedentes en el siglo XIX — como los proyectos de desecación del Lago de Almonte y Marisma Gallega de 1876 y 1877 (OJEDA RIVERA, 1987) — el proceso de transformación es más reciente y ha sido menos estudiado. Las actuaciones efectivas sobre el sistema hídrico (arroyos de Majaberraque y Rianzuela, caños de la Cigüeña, Guadiamar y Travieso) se iniciaron en 1944 con el Proyecto de Desagüe del río Guadiamar (CONFEDERACIÓN HIDROGRÁFICA DEL GUADALQUIVIR, 1944) que «R. Beca y Cía. S.L. Industrias Agrícolas», principal beneficiaria directa de la operación, ejecutó por contrata con financiación pública. La intervención del Estado se reguló mediante la aplicación de la Ley de 7 de julio de 1911, eligiéndose la fórmula de obra del Estado auxiliada por los particulares beneficiados. Una vez completada la primera etapa, esta misma sociedad continuó la

FiguRA 2. Modificaciones del sistema hidrológico natural de Doñana

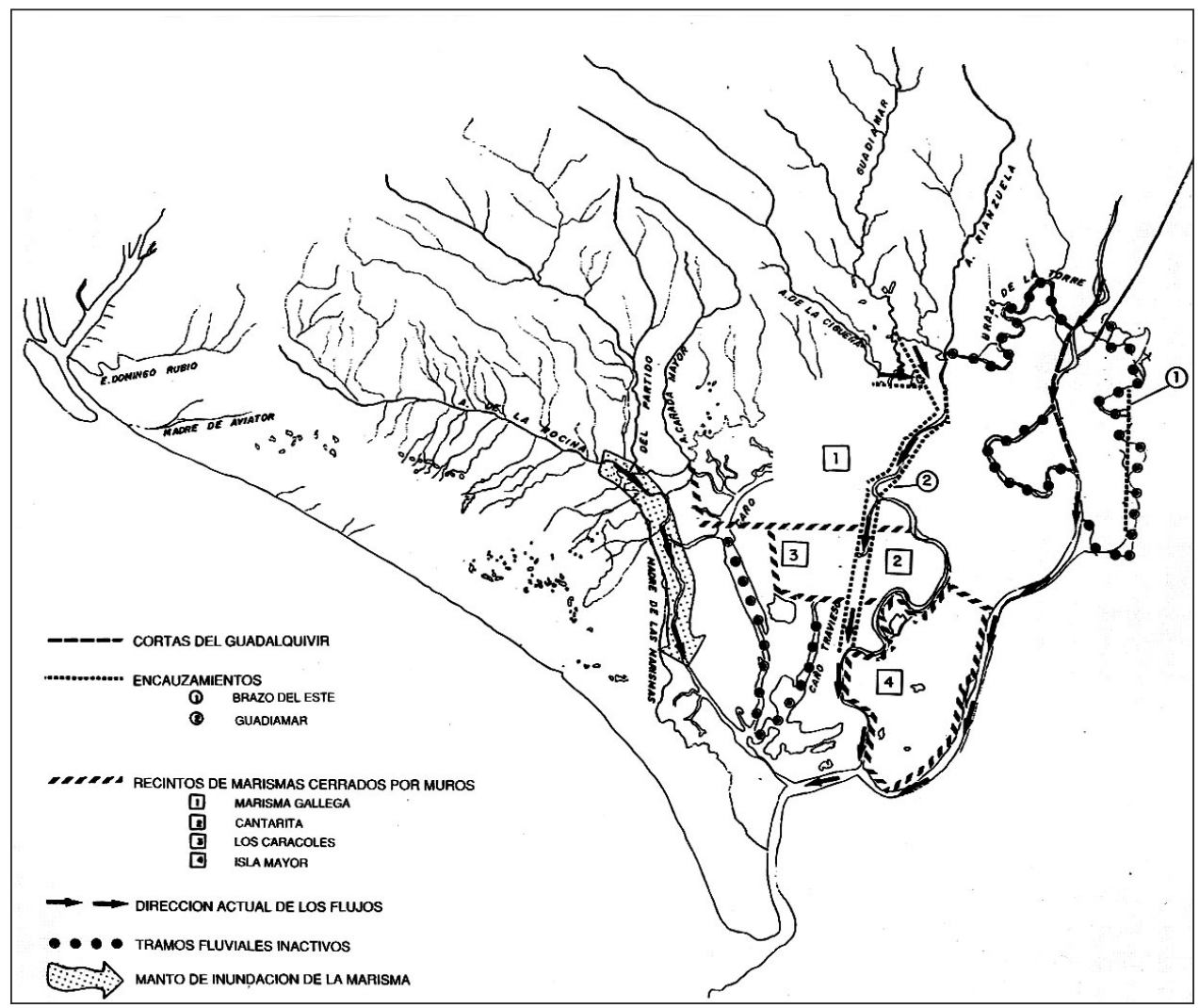

Fuente: Plan Director de Coordinación de Doñana y su Entorno, 1989. 
labor con la ejecución del muro de defensa de Isla Mayor entre Los Pobres y Vuelta de la Arena, al que siguió el Proyecto de Desecación de la Marisma Gallega o de Aznalcázar, que continuaba el encauzamiento del Guadiamar e incluía el muro trasversal de este a oeste que todavía hoy corta el flujo hídrico norte-sur que alimentaba la marisma (CONFEDERACIÓN HIDROGRÁFICA DEL GUADALQUIVIR, 1953).

Otra intervención coetánea de importancia estratégica desde un punto de vista territorial fue la construcción, a partir de 1952, del camino de Colinas a las Marismas de Aznalcázar (CONFEDERACIÓN HIDROGRÁFICA DEL GUADALQUIVIR, 1952) que arrancando de la carretera de Puebla del Río a esa última población, entroncó con la rasante de los muros incluidos en los proyecto anteriores, acondicionados para ese fin. En fecha tan tardía como la mencionada, esta obra constituyó la primera vía de acceso a 60.000 has. de marismas hasta ese momento inaccesibles durante varios meses al año.

Completadas estas tres operaciones, las Hermandades de Labradores de Villamanrique de la Condesa y de Puebla del Río - llama la atención la ausencia de Aznalcázar, titular de estos espacios pero vuelta de espaldas a ellos - solicitan la continuación y extensión de los trabajos. De la misma manera se manifiesta el Ayuntamiento de Hinojos que, insatisfecho por la defensa parcial que las marismas de su propiedad recibían de la intervención primeramente proyectada, plantea que la operación se extendiera hasta el caño de la Madre de las Marismas. Es entonces cuando se elaboran y ejecutan parcialmente el Proyecto de Desecación de Marismas de la Margen Derecha y el Proyecto de desagüe del Caño de Brenes, ambos de 1958 (CONFEDERACIÓN HIDROGRÁFICA DEL GUADALQUIVIR, 1958), cuya aplicación completa, frenada como veremos en 1966, hubiera supuesto la desaparición total de las Marismas de Doñana.

\section{Las aguas en el desarrollismo: gestión dominadora, despilfarradora y conflictiva}

La declaración de Doñana como Parque Nacional, el descubrimiento de la «bolsa de agua subterránea» del Acuífero 27 y la masificación del turismo veraniego van a significar cambios sustanciales en la percepción y la gestión de las aguas.

Mientras las tierras de Doñana son objeto de disputa entre los forestales de la Dirección General de Montes, para su repoblación con eucaliptos, los agrónomos del Instituto Nacional de Colonización, para su cultivo de arroz y los industriales del Instituto Nacional de Industria, para su producción de caucho (guayul), sus propietarios (burguesía gaditana fortalecida en la guerra civil) se unen a científicos nacionales y extranjeros y a naturalistas - cazadores - deportistas para convencer a Franco de la necesidad de conservar Doñana como Parque Nacional. El Programa M.A.B. de la UNESCO califica al tradicional «pantanal infecto» de las marismas de Doñana como área de especial interés entre las «zonas húmedas» de Europa y África (1962). La W.W.F. compra 6.800 has. de marismas y las cede al Estado, creándose la Estación Biológica de Doñana (1963).

Por otra parte, durante la ejecución de las obras de desecación anteriormente mencionadas, algunos propietarios de las fincas afectadas —entre ellos Leo Biaggi en esos momentos dueño de Las Nuevas, justo al sur del muro trasversal ya construido- solicitaron la modificación del trazado de la prolongación de los muros proyectados «de forma que se pudiesen hacer compatibles sus distintos intereses que, en algunos casos resultan encontrados». En 1966 el ingeniero Vicente Aycart Benzo, encargado del proyecto por el organismo estatal competente, concebía el problema en los siguientes términos: «Efectivamente las tierras situadas en le extremo Sur de la zona defendida, por ser muy bajas y salinas, tienen un mal aprovechamiento agrícola, aún después de saneadas. Su valor cinegético, por el contrario, es considerable, constituyendo una importante fuente de riqueza la abundancia 
de patos silvestres y de otras aves acuáticas. Así resulta fundamental para estas tierras respetar sus circunstancias actuales, no impidiendo las inundaciones periódicas con objeto de mantener las actuales charcas y lagunas donde tienen sus criaderos aquellas aves (CONFEDERACIÓN HIDROGRÁFICA DEL GUADALQUIVIR, 1966).

Al fin, en una Reunión de la Unión Internacional para la Conservación de la Naturaleza (U.I.C.N.) de Nueva Delhi y como aportación española al Año Internacional de Conservación de la Naturaleza, se declara el Parque Nacional de Doñana (1969), que — paradójicamente - resulta en sus orígenes un verdadero lujo útil para lavar la cara internacionalmente a un estado totalitario. Aquella declaración va a poseer el innegable valor de salvar a Doñana en unos momentos difíciles, pero su ejecución por un estado no democrático generará unas contradicciones y vicios que se observan tanto en el establecimiento de unos primeros límites del propio parque en los que pesa más la lógica fundiaria que la ecológica dejando fuera ecosistemas fundamentales, como en la carencia de un debate social sobre dicha declaración - en las mismas fechas se debatía democráticamente en Francia la posible declaración de Camarga (1963-73)—. Estas circunstancias y los acontecimientos paralelos que se están sucediendo en la zona, vinculados al desarrollismo de la misma, conducen a que el recién creado Parque Nacional de Doñana adquiera una doble función: foco de atracción de posibles beneficios económicos (turismo, compensaciones, planes...) y pantalla o escudo de iras populares ante fracasos, denuncias o quiebras de los planes de desarrollo agrícolas o urbanísticos balnearios.

Porque, en efecto, al mismo tiempo y en el marco paralelo y divergente de la fiebre desarrollista, en mayo de 1964, el Gobierno español había pedido a la F.A.O., un estudio que evaluase la potencia del acuífero Almonte-Marismas. Los estudios se desarrollaron en tres fases: un primer estudio hidrogeológico de la cuenca del Guadaquivir (1965-1968); una segunda fase (1969-1971) en la que se elaboró un proyecto piloto de utilización de aguas subterráneas para el desarrollo agrícola de la cuenca del Guadalquivir, incluido el anteproyecto de transformación en regadío de la zona Almonte-Marismas, lo que dio vía libre a la declaración de Interés Nacional y a la aprobación del Plan General de Transformación; y una tercera fase (1972-1974) en la que se completaron los estudios de suelos y las técnicas de sondeo. Los resultados del mencionado estudio establecieron que sobre una superficie permeable de $2.080 \mathrm{~km}^{2}$ se cuenta con un volumen de agua infiltrada de 337 $\mathrm{Hm}^{3} / a$ ño, con lo que podría regarse fácilmente más de 35.000 has. —26.500 has. de terreno aluvial arenoso y 8.600 de marisma-, alcanzando las reservas del acuífero los $7.000 \mathrm{Hm}^{3}$, lo que equivale a unos veinte años de lluvia (FAO, 1972). Además se aseguraba la ausencia de conexión entre los mantos acuíferos semi-confinados y confinados que se pretendía utilizar y las aguas superficiales y el manto freático dunar (GRANDE COVIÁN, 1987). En estos datos se fundamentó el origen de una nueva agricultura en arenas que transformó gran parte de los antiguos baldíos - algunos de cuyos parajes todavía seguían teniendo un exclusivo valor de uso- en fincas de altos valores de cambio. El motor más importante de estas transformaciones es el agua subterránea, que se convierte en un auténtico «tesoro enterrado» para la percepción de los habitantes de Doñana.

En el mismo cuadro de políticas de desarrollo hay que situar la apertura turística de España, que se inicia en la costa onubense con el Proyecto de Promoción Turística de la Costa de Huelva (1961-1963), que conduce a la declaración de interés nacional de la Promoción Turística de Matalascañas (Playas del Coto de Doñana) y al consiguiente Plan General de Ordenación desde Torre de la Higuera a Caño Guerrero, cuyas obras se inician en agosto de 1966, siendo declarado en 1968 Centro de Interés Turístico Nacional. También se necesitará agua subterránea dulce y limpia para los numerosos visitantes y residentes veraniegos de las playas. 
FIGURA 3. Principales intervenciones de transformación territorial en Doñana

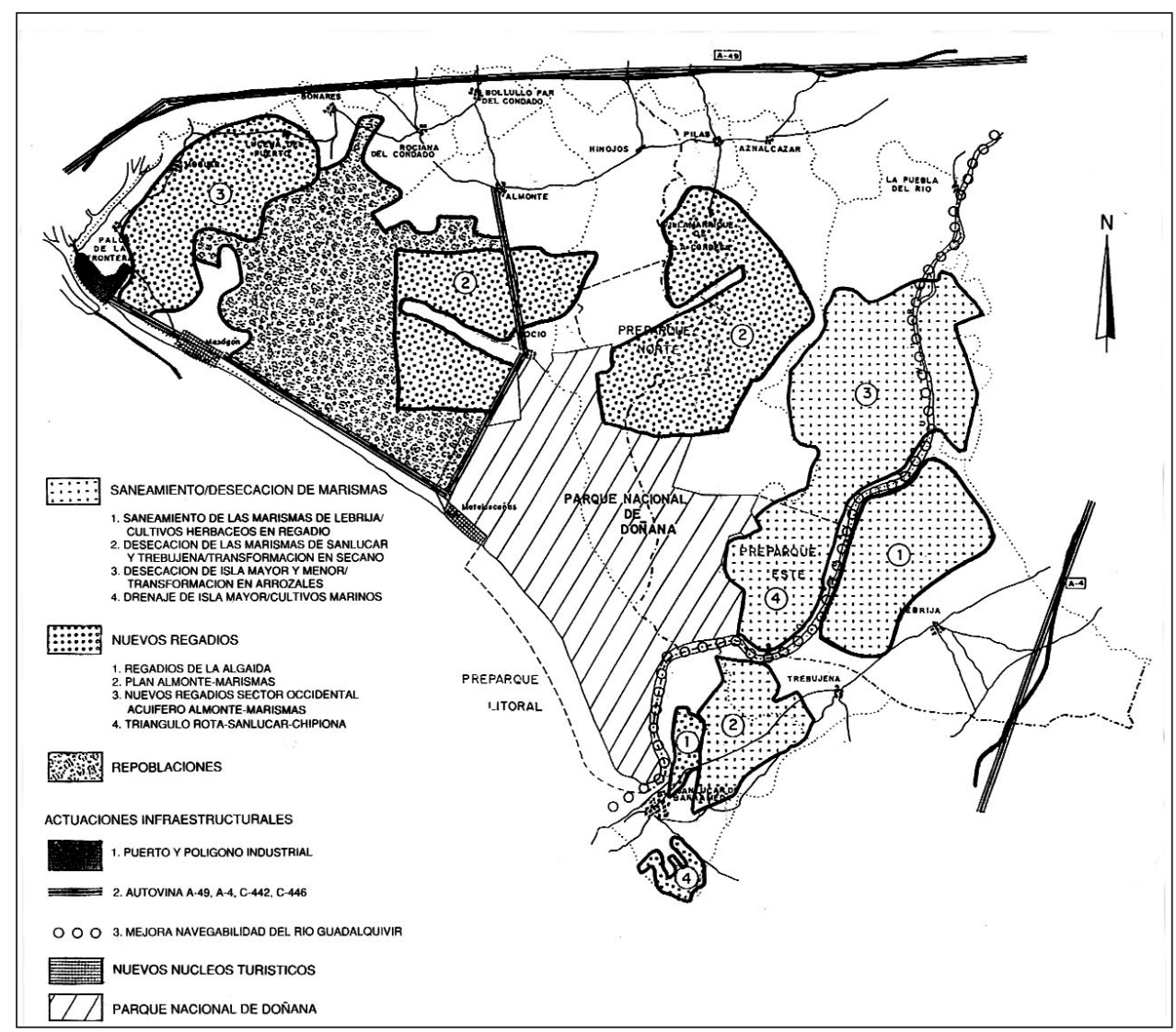

Fuente: Plan Director Territorial de Coordinación de Doñana y su Entorno, 1989.

Ya en la etapa final del franquismo y de transición a la democracia, uno de los caracteres más reconocidos de esta comarca, recién descubierta por el mercado, es la divergencia entre organismos oficiales sobre criterios de intervención sectorial y territorial, en un marco de oposición entre el desarrollismo y el nuevo paradigma clorofílico emergente y muy promocionado desde la C.E.E. Tal divergencia irá dando lugar a una percepción de Doñana como «affaire» continuo (carretera costera, Costa Doñana, recortes del Plan de regadío...) y a la progresiva conversión del Parque Nacional en signo de diferenciación social, de tal forma que sus sociedades más cercanas lo percibirán como recurso propio y las más lejanas como patrimonio mundial.

En esta etapa, las cantidades y las calidades de las aguas se convierten en crisoles de las contradicciones entre crecimiento económico — confundido con desarrollo y justificador de ciertos despilfarros y de procesos contaminantes de aguas - y conservacionismo - biologista, selectivo y muy exigente en cantidades y calidades de aguas, hecho ciertamente problemático si se tiene en cuenta que la máxima protección se sitúa al final de una cuenca hidrográfica y de un manto freático-. 


\section{Las aguas en la actualidad: conciencia del despilfarro y la contaminación y gestión importadora y restauradora}

Las ecofilosofías conformadoras del paradigma ambientalista, transformado en las últimas décadas en ideología del propio sistema económico despilfarrador (de la contestación radical a la domesticación y el «barniz verde») convierten en políticamente correcta la conciencia del despilfarro del agua en la comarca de Doñana. La última gran sequía pone en evidencia, por su parte, el impacto de las extracciones sobre el acuífero 27 y sus consecuencias ecológicas sobre el ecotono de la Vera. Y la catástrofe del Guadiamar se convierte asimismo en el detonante de una situación estructural de riesgo contaminador y transforma de políticamente correcta en absolutamente necesaria la estrategia restauradora de los sistemas hídricos de Doñana (Parque Nacional y Natural).

FiguRA 4. Proyecto de regeneración hídrica de Doñana en la década de 1980

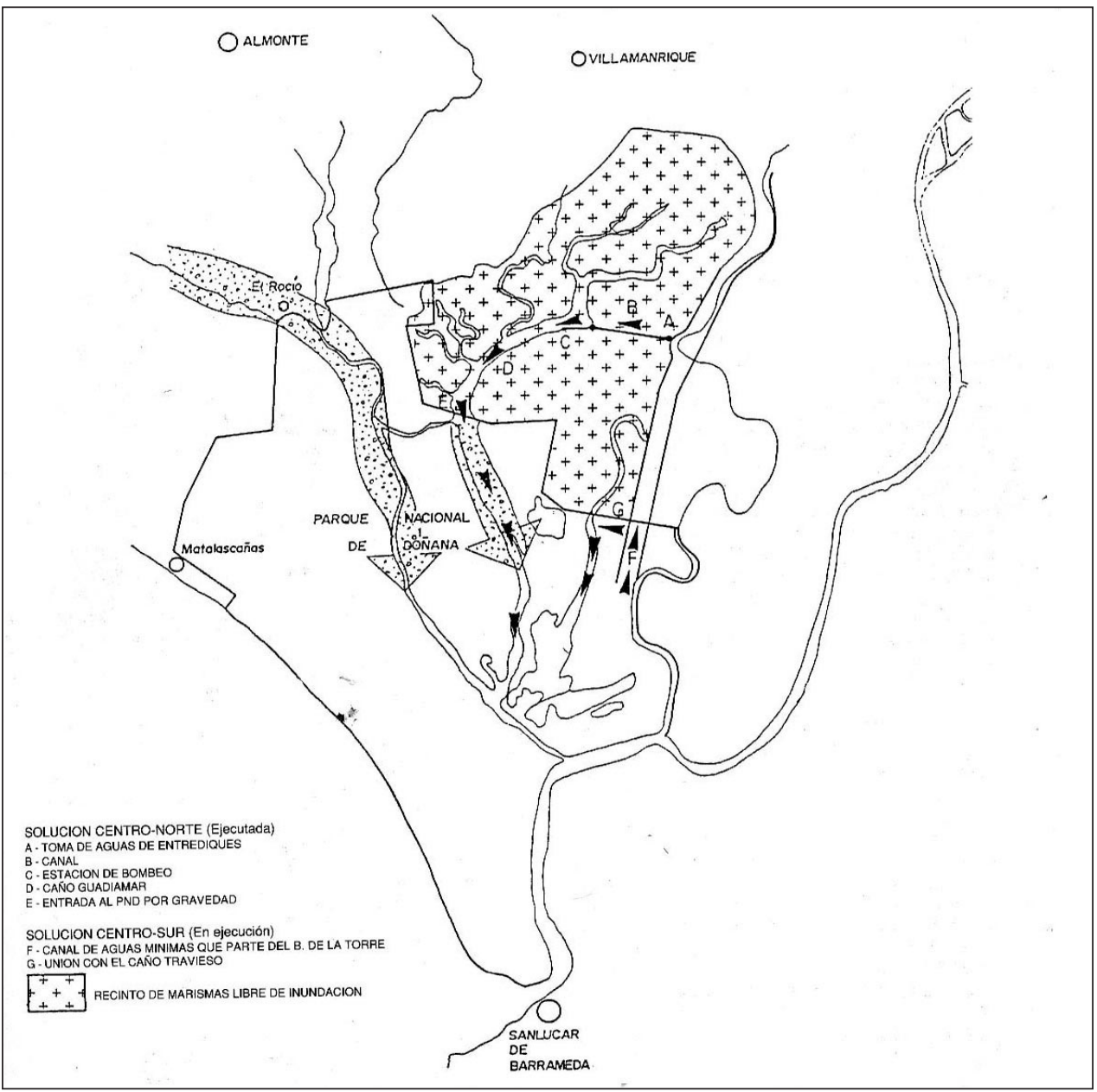

Fuente: Plan Director Territorial de Coordinación de Doñana y su Entorno, 1989. 
En función de los factores anteriores y de la necesidad no sólo ya de conservar, sino de restaurar algunos de los ecosistemas de los parques — nacional y natural— queda justificada una costosa y difícil estrategia de restauración de escorrentías y ecosistemas acuáticos. Esta estrategia tiene sus orígenes a comienzos de los años ochenta con dos operaciones que tenían como objetivo «la recuperación del equilibrio hídrico del Parque Nacional». La primera fue la restauración de la Montaña del Río, obra que impide que las aguas del río Guadalquivir y del mar entren en la Marismilla, al sur de Doñana. La segunda actuación, realizada conjuntamente por la Confederación Hidrográfica del Guadalquivir y el ICONA, consistió en la realización de las obras que se definieron como Regeneración Hídrica de Doñana y que consistieron en el intento (en buena parte fallido) de recuperar la funcionalidad hidrológica de los caños Guadiamar (solución Centro-Norte) y Travieso (solución Sur), eliminada como consecuencia de las intervenciones de desecación anteriormente mencionadas (SECRETARÍA DE ESTADO PARA LAS POLÍTICAS DEL AGUA Y EL MEDIO AMBIENTE, 1993).

Esta estrategia se continúa con la restauración de ciertos paisajes hídricos del Abalario (Ribetehilo, La Mediana) y se sigue desarrollando en los últimos años con los programas del Guadiamar (Corredor Verde) y de Doñana 2005 (restauraciones del sistema hídrico transformado y deteriorado con el desarrollo del Plan Almonte-Marismas: arroyos del Partido, Cañada Mayor, de la Juncosilla y del Portachuelo).

Pero, por otro lado, la emergencia de este territorio como espacio competitivo desde la producción agrícola extratemprana y desde el turismo masivo litoral justifica también el mantenimiento de una estrategia productivista, que, confrontada con la política de restauración recién mencionada, ya no sólo requiere la intensificación de recursos internos, como se hacía hasta ahora, sino la importación de recursos hídricos externos hacia Doñana.

Ya el riego de las marismas de la margen izquierda y de las islas Mayor, Menor y Mínima a partir de caudales regulados, almacenados en los embalses de Tranco de Beas, Iznajar o la Breña, podría ser considerado como una forma de importación de aguas a la comarca de Doñana. Pero esta nueva tendencia explícitamente importadora se inicia realmente con el abandono de las aguas subterráneas locales en el abastecimiento de las poblaciones del entorno de Doñana — que pasan a depender de los sistemas de abastecimiento del área metropolitana de Sevilla y del conjunto del Condado- y tiene su gran salto hacia delante en el proyecto de trasvase directo desde la cuenca del Guadiana.

Desde su aparición en el Anteproyecto de Plan Hidrológico Nacional de 1993, con 100 $\mathrm{hm}^{3} /$ año que se incrementaron a $200 \mathrm{hm}^{3} /$ año en el documento de 1994, la idea del trasvase del Guadiana a Doñana (cuenca del Guadalquivir) ha gravitado como factor fundamental - pero al mismo tiempo externo y, una vez más, concebido en instancias externas al ámbito- en el análisis y debate de soluciones para la gestión de los recursos hídricos de la comarca, distorsionando las magnitudes del problema e incrementando el contexto de incertidumbre que lo rodea. Desde una perspectiva de política territorial, es de destacar que el plan de ordenación del territorio vigente en la comarca (el Plan Director Territorial de Coordinación de Doñana y su Entorno de 1989) y el Dictamen de la Comisión Internacional de Expertos (1992) no contemplaran la medida que desde la planificación sectorial de aguas se estaba gestando. El Plan Hidrológico Nacional aprobado en 2001 no incluyó finalmente el trasvase intercuencas que comentamos. Sin embargo, la actual situación se caracteriza por la inclusión en las alegaciones del Gobierno autonómico al Plan Hidrológico de la petición de un trasvase del Guadiana al Condado de Huelva y Entorno de Doñana de hasta $150 \mathrm{hm}^{3} /$ año, en una primera fase, y de hasta $200 \mathrm{hm}^{3} /$ año para el bajo Guadalquivir, en una segunda fase. En el contexto de los volúmenes de agua actualmente manejados en la comarca (en torno a $60 \mathrm{hm}^{3} /$ año) estas cifras conllevarían unos procesos de cambio e 


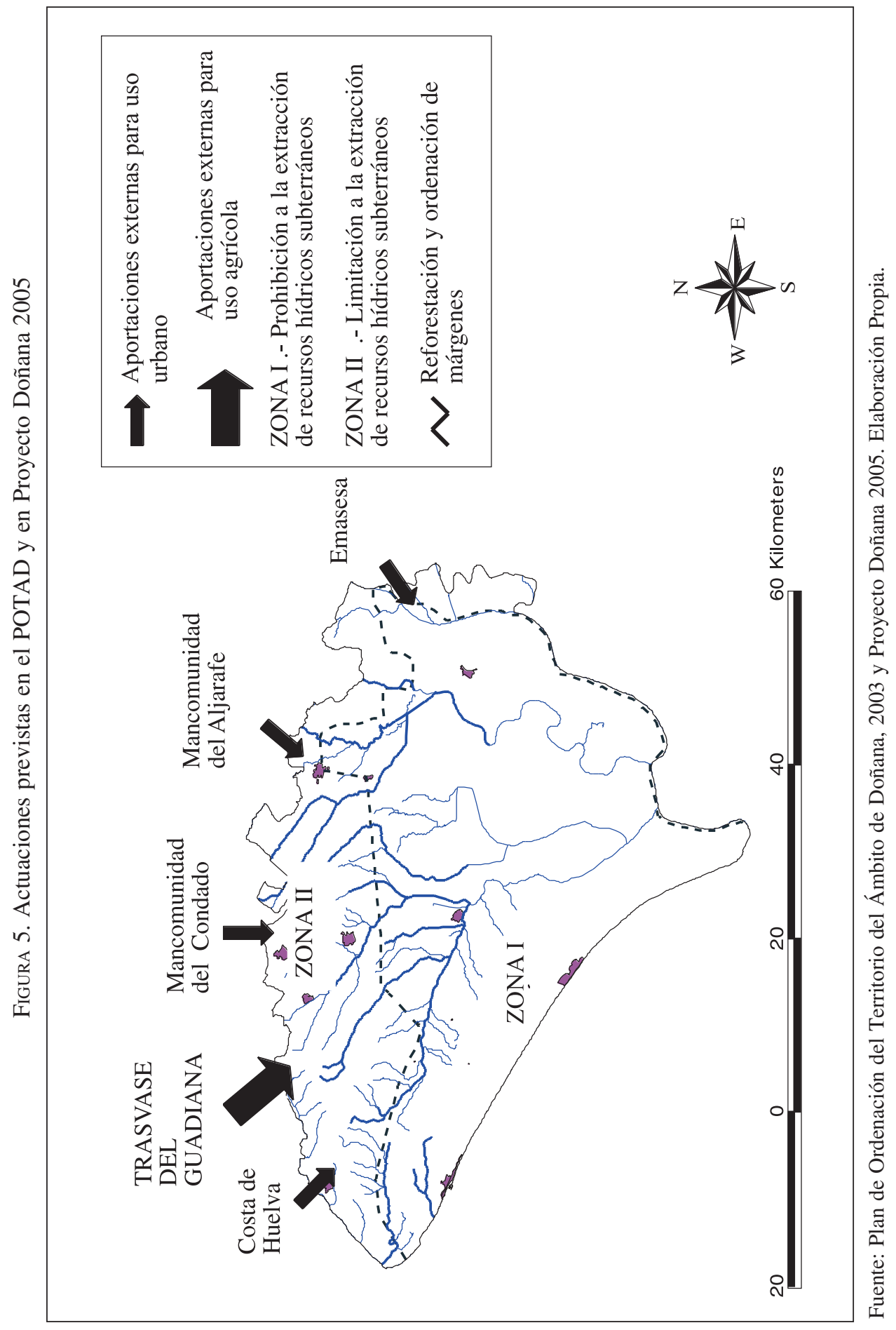


intensificación de usos, que requerirían una atención muy atenta por parte del documento de ordenación del territorio en curso de aprobación (Plan de Ordenación del Territorio, ámbito de Doñana, octubre 2000 y diciembre de 2003) que sí menciona la propuesta, pero que no justifica la asignación de estos volúmenes de agua ni analiza sus impactos (MORAL, 2001 y 2002).

Programas de restauración hídrica y proyectos de trasvase que, sin duda, prolongan y profundizan una conflictividad ya enquistada y unos mecanismo de intervención que no son ajenos — como hemos podido ver en las anteriores páginas — a la citada conflictividad, producto típico - junto con la normalización de lo transitorio, la conformación de islas territoriales yuxtapuestas o enfrentadas y la consolidación de la dependencia económica y social - de unos modelos coloniales de explotación y de poblamiento que no se superan, sino que se consolidan en la ya europea y paradigmáticamente subvencionada comarca de Doñana.

\section{Conclusiones}

El territorio de Doñana llega a la época moderna como un espacio vacío, dominado por actividades y aprovechamientos localmente valiosos pero básicamente marginales al sistema productivo que ya en el siglo XVIII empieza a configurarse. Grandes extensiones pertenecientes al patrimonio señorial de Medinasidonia y a los bienes concejiles, desvinculados y privatizados en su mayor parte a los largo del siglo XIX y primeras décadas del $\mathrm{XX}$, se convierten en el campo de actuación de aquellas entidades que pueden disponer de la concentración de recursos financieros imprescindible para acometer su transformación: importantes sociedades capitalistas que se enfrentan con un espacio sin condicionar, sin estructuras socioeconómicas limitantes, sin tradiciones culturales que respetar. Un espacio abierto a la iniciativa de empresas exclusivamente sensibles a los imperativos del mercado y a la rentabilidad de la inversión. Estos son los factores que explican la gran escala de los módulos de la intervención, la intensificación y fragmentación de los aprovechamientos, acometidos recurso a recurso, y la variabilidad de las orientaciones especulativas o productivas en relación con los factores mercantiles presentes en cada momento. Estos rasgos se han plasmado en fenómenos como la acelerada circulación de la titularidad de las concesiones de saneamiento de marismas de manos de unas compañías a otras, pero también en la notable capacidad de adaptación a las coyunturas de aquellas actividades más rentables y en la destacada capacidad de innovación tecnológica.

Pero por encima de todo, el elemento esencial del proceso es la presencia del Estado. Primero como portavoz y difusor del pensamiento agrarista y colonizador frente al tradicional sistema agro-ganadero-cinegético-recolector. Más tarde como factor de soporte de la empresa privada, por medio del respaldo político y de las subvenciones a sus inversiones. Paralelamente, se inicia su intervención directa, que cada vez adquiere mayor generalidad e intensidad. Así pues, el alto coste de la puesta en valor de este territorio, la potencia y concentración de los recursos necesarios para hace frente a su transformación productiva determinan tanto la ausencia de una tradición campesina, que sin embargo está presente en el espacio perimarismeño (viñedo del Condado, olivar del Aljarafe), como el protagonismo de la gran empresa capitalista en la intervención. A ella se superpone, subsidiándola y respaldándola políticamente, el organismo de mayor nivel político-administrativo, que se convierte progresivamente en el factor esencial de la gestión espacial.

Los instrumentos específicos del Estado, junto a los habituales en cualquier otro espacio, son dos: el monopolio sobre el control del ciclo artificializado del agua del que dependen la totalidad de las actividades que se desarrollen en la gran zona húmeda que 
constituye Doñana y, más recientemente, la legislación medioambiental. Efectivamente, si la transformación productiva ha tenido en el Estado a su principal agente, la política de conservación ha venido a aumentar esta presencia determinante. De la política de puesta en valor general del conjunto del territorio se pasa a la división administrativa del mismo en zonas transformadas y zonas a conservar. A lo largo del proceso se asiste a una intensificación de la presencia y la capacidad decisoria de los organismos de mayor nivel políticoadministrativo vigente en cada momento, lo que en la actualidad se refleja en la presencia creciente de la Unión Europea. De esta manera, el proceso de transformación-conservación de Doñana se ha desenvuelto a impulsos de una dinámica ajena en sus grandes rasgos a la capacidad de decisión de las sociedades locales, que se han visto afectadas por los cambios de relaciones socioeconómicas inducidas por las diferentes políticas de fomento o conservación. El modelo de «darwinismo cultural» típico y tópico en las gestiones de espacios naturales protegidos - expertos que entienden, políticos que deciden, comunidades locales que deben ser sensibilizadas - llega en este mundo de Doñana a convertirse en paradigmático (OJEDA, 1999b), generando unas actitudes populares que caminan del enfrentamiento a la resignación subsidiada.

\section{Referencias}

BETHEMONT, J. y VILLAIN-GANDOSSI, Ch. (1987): Les Deltas Méditerranéens, Centre Européen de Coordination de Recherche et de Documentation en Sciences Sociales, Viena.

CONFEDERACIÓN HIDROGRÁFICA DEL GUADALQUIVIR (1944): Proyecto de Desagüe del río Guadiamar, CHG/DGOH, Sevilla.

CONFEDERACIÓN HIDROGRÁFICA DEL GUADALQUIVIR (1952): Proyecto de camino de Colinas a las Marismas de Aznalcázar, CHG/DGOH, Sevilla.

CONFEDERACIÓN HIDROGRÁFICA DEL GUADALQUIVIR (1953): Proyecto de desecación de la Marisma de Aznalcázar, CHG/DGHO, Sevilla.

CONFEDERACIÓN HIDROGRÁFICA DEL GUADALQUIVIR (1958): Proyecto de Desecación de Marismas de la Margen Derecha, CHG/DGOH, Sevilla.

CONFEDERACIÓN HIDROGRÁFICA DEL GUADALQUIVIR (1966): Proyecto reformado del de desecación de las Marismas de la margen derecha, CHG/DGHO, Sevilla.

CHAPMAN, A. y BUCK, W. J. (1989): La España inexplorada, Sevilla, Junta de Andalucía. (Texto original en inglés, 1910).

FAO (1972): Proyecto piloto de utilización de aguas subterráneas para el desarrollo agrícola de la cuenca del Guadalquivir. Anteproyecto de transformación de regadío de la zona AlmonteMarisma, Informe técnico I AGL: SF/SPA16, Madrid.

FERNÁNDEZ PALACIOS, J.M., M.J. MARTOS SALINERO y J.C. RUBIO GARCÍA (1990): «Las marismas atlánticas andaluzas», Quercus, núm. 54.

GONZÁLEZ ARTEAGA, A. (1993): Las Marismas del Guadalquivir: etapas de su aprovechamiento económico, C.P. Antonio Cuevas, Ayto. de Puebla del Río (Sevilla).

GONZÁLEZ FARACO, J.C. (1997): Cultura y Educación Ambiental en Doñana. Bases para una intervención. Servicio de Publicaciones de la Universidad de Huelva, 1997, 360 pp.

GRANADOS, M. y OJEDA, J.F. (1994): Doñana. Paisaje y poblamiento. Edificaciones en el Parque Nacional. Consejería de Obras Públicas y Transportes. Dirección General de Arquitectura y Vivienda, Junta de Andalucía, Sevilla. 142 pp.

GRANDE COVIÁN, R. (1978): El estuario del Guadalquivir y su problemática agrosocial, Ministerio de Agricultura, IRYDA, Madrid.

JUNTA DE ANDALUCÍA (1989): Plan Director Territorial de Coordinación de Doñana y su Entorno, Consejería de Obras Públicas y Transportes, Dirección General de Urbanismo, Sevilla, $297 \mathrm{pp}$.

JUNTA DE ANDALUCÍA (2000 y 2003): Plan de Ordenación del Territorio del Ámbito de Doña$n a$, Consejería de Obras Públicas y Transportes, Sevilla. 
MORAL ITUARTE, L. DEL (1989): «Un intento frustrado de acondicionamiento del Guadalquivir. La actuación de la Real Compañía de Navegación en la primera mitad del siglo XIX: nuevas aportaciones y replanteamiento geo-histórico de un tema polémico», Mélanges de la Casa de Velázquez, París, 1989, tomo XXV, pp. 327-353.

MORAL ITUARTE, L. DEL (1990): «Bonificación de marismas y privatización de comunales: el caso de la Isla Mayor del Guadalquivir (1825-1893)», Archivo Hispalense. Revista Histórica, Literaria y Artística, Sevilla, núm. 224, 1990, pp. 23-34.

MORAL ITUARTE, L. DEL (1991): La obra hidráulica en la cuenca baja del Guadalquivir (siglos XVIII-XX). Gestión del agua y organización del territorio. Sevilla, Servicio de Publicaciones de la Universidad de Sevilla, Consejería de Obras Públicas y Transportes, Ministerio de Agricultura, colección KORA, 1991.

MORAL ITUARTE, L. DEL (1993a): «El cultivo del arroz en las marismas de Doñana: situación actual y perspectivas», Agricultura y Sociedad, Madrid, Ministerio de Agricultura Pesca y Alimentación, núm. 67, pp. 205-233.

MORAL ITUARTE, L. DEL (1993b): «Las Marismas del Guadalquivir», en OJEDA RIVERA, J. (coord.): Intervenciones Públicas en el Litoral Atlántico Andaluz. Efectos Territoriales. Sevilla, Junta de Andalucía, Consejería de Cultura y Medio Ambiente, Agencia de Medio Ambiente, 1993, pp. 31-41.

MORAL ITUARTE, L. DEL (1994): «Regadíos y estructuras de poder en la Baja Andalucía», en ROMERO, J. y C. GIMÉNEZ (eds.): Regadíos y estructuras de poder, Alicante, Instituto de Cultura «Juan Gil-Albert», Diputación de Alicante, 1994, pp. 215-240.

MORAL ITUARTE, L. DEL (2001): «Planification hydrologique et politique territoriale en Espagne», Hérodote. Revue de Géographie et de géopolitique, núm. 102, tercer trimestres, pp. 87-112.

MORAL ITUARTE, L. DEL (2002): «El tratamiento del agua en la ordenación de territorio en Andalucía», Andalucía Geográfica, núm. 9, mayo, pp. 43-55.

MOUNTFORT, G. (1994): Retrato de una tierra salvaje. La historia de las expediciones al Coto de Doñana. Madrid, Patronato del Parque Nacional de Doñana. (Texto original en inglés, 1958).

OJEDA RIVERA, J.F. (1985): «Le Parc National Doñana et son environnement», en Revue géographique des Pyrénées et du Sudouest. T.56/2, avril-juin 85. Toulouse, pp. 225-242.

OJEDA RIVERA, J.F. (1987): Organización del territorio en Doñana y su entorno próximo. (Almonte). Siglos XVIII-XX. Mº de Agricultura - ICONA. (Monografías, 49). Madrid. 456 p.

OJEDA RIVERA, J.F. (1990): «Doñana paisaje cultural -Doñana cultural landscape», en VV.AA. Doñana: La naturaleza en España (Edición bilingüe). Ed. Lunwerg, Barcelona, pp. 18-25

OJEDA RIVERA, J.F. (1992): «Políticas forestales y medio ambiente en Doñana y su entorno» en Agricultura y Sociedad, $\mathrm{n}^{\circ}$ 65, Ministerio de Agricultura, Pesca y Alimentación, Madrid, pp. 303-357.

OJEDA RIVERA, J.F. (1993): Doñana:Esperando a Godot. Instituto de Desarrollo Regional, Sevi1la. Cuaderno, $\mathrm{n}^{\circ} 31.84 \mathrm{pp}$.

OJEDA RIVERA, J.F. (coord.) (1993): Intervenciones públicas en el litoral atlántico andaluz. Efectos territoriales. Agencia de Medio Ambiente, Junta de Andalucía, Sevilla. 154 pp.

OJEDA RIVERA, J.F. (1999a): «Una aproximación interpretativa a la catástrofe del Guadiamar», en Cuchará y paso atrá, $\mathrm{n}^{\circ}$ 7. Colectivo de Estudios Marxistas, Sevilla, pp. 49-56.

OJEDA RIVERA, J.F. (1999b): «Espacios Naturales Protegidos y Desarrollo Sostenible» en Geografía y Espacios Protegidos. Asociación de Geógrafos Españoles y Federación de Espacios Naturales Protegidos de Andalucía. Sevilla, pp. 273-286.

OJEDA RIVERA, J.F., GONZÁLEZ FARACO, J.C. y VILLA DÍAZ, J. (2000): «El paisaje como mito romántico. Su génesis y pervivencia en Doñana», en MARTÍNEZ DE PISÓN, E. (Coord.) Estudios sobre el paisaje. Madrid, Universidad Autónoma de Madrid y Fundación Duques de Soria. Colección de Estudios, nº 67, pp. 343-357.

PICON, B. (1985): «Le Camargue, gestion hydraulique et rapports sociaux» en DESJEUX y otros, L'eau. Quels enjeux pour les sociétés rurales, Éditions L'Hramattan, Paris.

PICON, B. y OJEDA, J.F. (1993): «De la nature 'ressource' à la nature 'institutionalisée' dans les deltas du Rhône et du Guadalquivir» en Revue Méditerranée. n 3-4, Institute de Géographie, Aix-en-Provence, pp. 69-79. 
REGUERA RODRÍGUEZ, A. (1986): Transformación del espacio y política de colonización. El Bajo Guadalquivir, Diputación de León, Universidad de León.

SANCHO, N.M. (1858): Memoria histórica de la extinguida sociedad denominada Compañía de Navegación del Guadalquivir y Canal Fernandino, Imprenta Librería Española y Extranjera, Sevilla.

SECRETARÍA DE ESTADO PARA LAS POLÍTICAS DE AGUA Y EL MEDIO AMBIENTE (1993): La gestión hidráulica en el Parque Nacional de Doñana, Ministerio de Obras Públicas y Transporte, Madrid.

VALVERDE, J.A. (1990): «Doñana y el Parque Nacional. Los primeros pasos, 1952-1975, en Doñana, Parque Nacional. La naturaleza en España, Ministerio de Agricultura, Pesca y Alimentación, ICONA, Madrid.

VANNEY, J.R. (1970): L'hydrologie du Bas Guadalquivir, Instituto de Geografía Aplicada del Patronato Alonso de Herrera, Consejo Superior de Investigaciones Científicas. 